\title{
The Value Equation in Pediatric Health Care
}

\author{
Robert W. Steele, MD, MBA \\ Jayant K. Deshpande, MD, MPH, FAAP* \\ Angela Green, PhD, RN, FAHA
}

\author{
Address \\ *Arkansas Children's Hospital, 1 Children's Way, Slot 301, Little Rock, AR, 72202, \\ USA \\ Email: DeshpandeJK@archildrens.org
}

Published online: 28 November 2016

(C) Springer International Publishing AG 2016

This article is part of the Topical Collection on Pediatric Health Care Administration

Keywords Pediatrics $\cdot$ Healthcare $\cdot$ Value-driven models $\cdot$ Stakeholders $\cdot$ Arkansas $\cdot$ Children's hospital $\cdot$ Children . Patient centereed medical home $\cdot$ Clinically integrated network - Accountable care organization · Michael Porter · ACE Kids - Triple Aim • Healthcare costs

\section{Opinion Statement}

One of the biggest buzzwords in healthcare today is "value.". However, the definition of value in healthcare has gone through evolution since the 1960's and has largely been defined by the healthcare industry rather than consumers. Today, the framework from which healthcare experts largely define value is the Triple Aim. First described by an economist rather than a clinician, the Triple Aim can be translated into a value equation: Value $=$ outcome/cost. Skeptics may assume this is code for cost reduction alone. But it is the numerator that tends to resonate more with pediatricians because outcomes are dependent upon the condition of the patient and defined by improved health. Yet, there remains poor agreement about what the indicators of children's health are or the timeframe in which those outcomes should be measured. Pediatric outcomes studies that also include cost are numerous but favor constrictions within service lines, specific disease processes, or outpatient or inpatient settings. This often limits true measurement of value because accounting for all the variables that influence the value equation are is not adequately captured. Acquiring all the data requires defining the population and aligning the providers within an agreed upon care model. Currently, there is no standard way to do this, but several models have become more prevalent including the patient- centered medical home, clinically integrated networks, and accountable care organizations. Unfortunately, published pediatric studies regarding the success or failure of these models are virtually non-existent. Efforts abound locally, regionally, and nationally to increase value in pediatric healthcare delivery. For example, pediatricians in Phoenix are putting compensation at risk to improve quality. Arkansas Children's Hospital is establishing the country's first statewide 
pediatric clinically integrated network. Congress is considering bipartisan action with The Advancing Care for Exceptional Kids Act. Time will tell which models are successful.

\section{Introduction}

One of the biggest buzzwords in healthcare today is "value." There are value-driven models of care, valuebased purchasing requirements, patient-centered value outcomes metrics, and value-based incentives. Hospitals and health systems are moving from volume to value reimbursement models, and the Centers for Medicare and Medicaid Services (CMS) has formally declared that $90 \%$ of its payments will be based on value by 2018 . In addition, CMS has announced a proposed rule to test value-based pricing for prescription medications $[1 \bullet, 2]$. In most industries, the definition of value is driven by consumers paying for the product or service. But the health care industry in the USA seems to be different, at least historically. The definition of value may differ based upon the person, organization, or agency answering the question. The number of stakeholders interested in this definition is large, and the relationships between the stakeholders are complex. Even when one narrows the focus to pediatric health care, the complexity does not shrink and in many aspects actually increases. So then, what is value in pediatric health care? Or more importantly, what should it be?

\section{Background}

The codifying of pediatric healthcare value in the modern era likely originated with the establishment of the medical home as defined by the American Academy of Pediatrics (AAP) publication of The Standards of Child Health Care in 1967. Recognizing the lack of communication and coordination of care particularly for children with special health care needs, this publication defined the medical home as a physical place and central source for a child's pediatric records comprehensive of all the care the child received by any provider. While the term, value, was not used as in today's vernacular, the authors suggest benefit by driving down inefficiency and improving care. The medical home concept has gone through many iterations since that time including two AAP policy statements which outlined the characteristics of a medical home without specifically defining its value. In 2007, the AAP and the American Academy of Family Physicians (AAFP) collaborated in the publishing of Joint Principles of the Patient-Centered Medical Home. This joint statement was the first time the medical home paradigm included quality, safety, patient experience, and reimbursement for children's care ostensibly as a value proposition.

The same year of the AAP/AAFP joint statement, the Institute for Healthcare Improvement (IHI) began recruiting organizations from around the world to participate in a collaborative to implement what became known as the Triple Aim. The 141 participating organizations included health care systems, hospitals, health care insurance companies, and others closely tied to health care [3]. In an article published in 2008, researchers from IHI posited that, in order to improve US health 
care, it was necessary to pursue a system of linked goals called the Triple Aim: "improving the individual experience of care; improving the health of populations; and reducing the per capita costs of care for populations." [4] Don Berwick, former Administrator for CMS and a pediatrician himself, used these principles to advance a CMS agenda after leaving IHI in 2010. Eight years later, the Triple Aim remains the language and framework from which many health systems, hospitals, and physicians frame the value in healthcare. The pediatric literature contains multiple studies framed within the Triple Aim on topics as diverse as adolescents transitioning from the pediatric to the adult health care system, inborn errors of metabolism, and diabetic ketoacidosis.

The Triple Aim can be translated into a value equation. It is interesting, however, that one of the most cited definitions of value in health care originated not from a physician but from an economist [ $5 \bullet \bullet$. Michael Porter has largely spent his career at Harvard Business School defining value and strategies to achieve value in many industries. It is only relatively recently his attention has moved to health care, but his influence is palpable in pediatrics. He is routinely quoted in articles from the Children's Hospital Association, the AAP, and the pediatric medical literature [6-8].

He defines value as the health outcomes achieved per dollar spent. Unpacking that simple equation can be tricky. Depending upon one's own personal experience, health care providers may be skeptical and assume it is code for cost reduction alone. It is important to stress the numerator, but defining outcomes can be challenging and measuring those outcomes even more so. The value must be defined around the patient and measured by the outcomes achieved rather than process measure improvement. Outcomes are dependent upon the condition of the patient and defined by improved health. However, there is poor agreement about what the indicators of improved health in children are or even the timeframe in which they should be measured [9]. Data analytic tools and the databases from which they can pull still remain largely in siloes. So, pediatric clinicians often resort to more easily measureable process metrics rather than overall outcomes. Nonetheless, it is this equation by which most payers define value when devising more progressive ways to reimburse health care providers.

Pediatric experience in measuring value

Alignment of the health care system in order to effectively manage any given defined population and increase value is still relatively young. There are numerous pediatric studies looking at outcomes and cost within service lines such as cardiovascular surgery, within defined disease processes such as bronchiolitis, within primarily outpatient populations such as adolescents, or confined to the inpatient setting such as the neonatal intensive 
care unit (NICU). Even in almost exclusively inpatient settings, such as the NICU, many of the patient outcomes that drive value can only be measured after discharge. Accounting for all the variables that influence outcomes and cost is often difficult without a comprehensive way of capturing all the data within that population across the continuum of care. Effectively improving care and measuring these variables require alignment of providers within an agreed upon care model.

Currently, there is not an agreed upon way to align physicians, hospitals, and other health care providers to achieve increased value, but several have become more prevalent (Fig. 1). These include patientcentered medical homes (PCMH), clinically integrated networks (CIN), and accountable care organizations (ACO). The published success in achieving value through any one of these constructs has been mixed in adult studies. The pediatric reported experience is not mixed; it is virtually non-existent. The first published study specifically measuring value achieved in a pediatric ACO only recently came from Nationwide Children's in 2015. Investigators measured their own Medicaid ACO historical cost of care and gathered comparison statewide Ohio Medicaid fee-forservice and managed care cost histories. While no significant improvement in quality measures were achieved, they did not get worse. At the same time, there were modest cost savings compared to the other groups during the same time period [10]. This one study does not set the standard, of course, but it is an excellent first step at reporting results in terms of the value equation.

Another confounding problem in defining value is that the definition of what lowered cost actually means is variable. While there appears to be some agreement for "total cost of care" being the definition of cost when discussing populations of patients, even that can be confusing. For example, does lowered cost mean lower as compared to a previous time frame or lower than what otherwise would have been expected? To make things even more puzzling, specific health care categories may be excluded from total cost of care calculations. Consider that in 2014, per capita health care spending for children covered by employer-sponsored insurance was $\$ 2,660$ which was a modest increase of $3.5 \%$ from the previous year. However, spending on brand name prescriptions increased by $6.8 \%$, the fastest spending growth rate observed for any service category in that year [11]. Yet, often these bigger drivers of cost within any given pediatric population are excluded from analysis. They are also a common target for exclusion when organizations negotiate value-based reimbursement contracts with payers.

\section{How to increase value in pediatric healthcare delivery}

Health care providers, hospitals, health system, and government payers have tried multiple strategies over the last few decades to increase the value of health care without much success. On the quality side, the US ranks 26th in the world in infant mortality rates. Burundi, Rwanda, Tanzania, and Uganda all have measles vaccination rates higher than the USA. Meanwhile, health care spending per capita is the highest in the world [12]. There are certainly nuances to any specific metric that could be argued, but taken as a whole, these findings suggest that the 


\section{Conclusion}

value the pediatric health care industry in the US delivers could be improved. This requires a restructuring of the settings and operations of children's health care.

Congress, in conjunction with a number of stakeholders, are already considering various alternatives. The Advancing Care for Exceptional Kids Act of 2015 (ACE Kids Act) is a proposal to improve how care is delivered to America's children with complex medical conditions on Medicaid. Proponents of this Act define its value in the terms described by Porter:

- Improve coordination of care for children to reduce the burden on families

- Address problems with fragmented care across state lines

- Gather national data on complex conditions to help researchers improve treatments for rare diseases

- Potentially save an estimated $\$ 13$ billion over its first 10 years, compared to the current system

Under the ACE Kids Act, eligible children would be assigned to a nationally designated children's hospital network. The networks would then coordinate services for these children across the continuum of care. They would include venues and providers in home, primary, ambulatory, acute, and post-acute care settings.

In order to care for children other than the medically complex, similar capabilities are being developed around the country through other provider networks often organized through children's hospitals. At Arkansas Children's Hospital, strategies are being established to achieve the Triple Aim through the country's first statewide pediatric clinically integrated network. This physician-led, value-based organization of pediatric providers is coming together organized around the patient and the medical condition. This includes those children with complex medical needs. Metrics measured will favor outcomes over processes, and those outcomes measures will be ones that matter to patients and their families rather than exclusively what researchers, payers, or individual health care providers desire. The total cost of care will also be measured along with subsets of costs depending upon the individual disease state. Integrated delivery systems such as this allow for a meaningful conversation to occur regarding what constitutes the right care for the right patient in the right setting at the right time. In Arkansas, where a large portion of the state is very rural, it also allows for an expanded geographic reach which can meaningfully improve the overall health of children at a lower cost.

The health care share of the US gross domestic product is expected to rise from $17.4 \%$ in 2013 to $19.6 \%$ by 2024 . Most policy makers and economists find this growth rate unsustainable. Without revolutionary change driven by the healthcare industry, government and private payers will step in to force a shift that might focus more on the costs than outcomes. In this early state of defining value in pediatric healthcare, providers have a unique opportunity to influence the definition, and thus, the future of healthcare delivery for children in our country. Moving forward, identifying the outcomes that matter to children, 
adolescents, and families is a critical next step. Now is the time for intensive efforts to build coordinated, collaborative models of care that support all three components of the Triple Aim.

\section{Compliance with Ethical Standards}

Conflict of Interest

Robert W. Steele, Jayant K Deshpande, and Angela Green declare that they have no conflict of interest.

Human and Animal Rights and Informed Consent

This article does not contain any studies with human or animal subjects performed by any of the authors.

\section{Appendix}

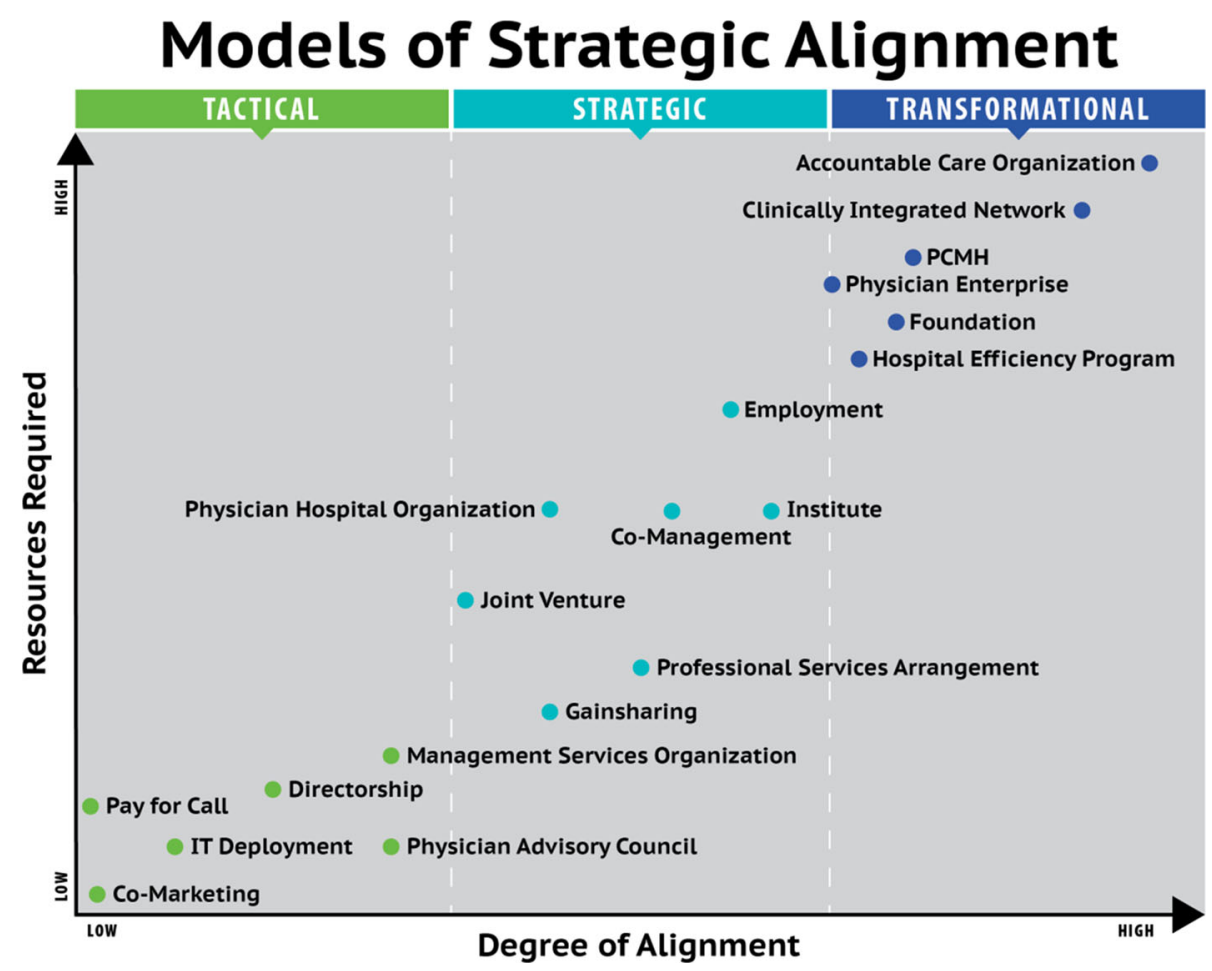

Fig. 1. Models of strategic alignment. 


\section{References and Recommended Reading}

Papers of particular interest, published recently, have been

highlighted as:

- Of importance

•- Of importance

1. Burwell SM. Setting value-based payment goals-HHS efforts to improve U.S. health care. N Engl J Med. 2015;372:897-9. doi:10.1056/ NEJMp1500445.

Excellent synopsis of how the Department of Health and Human Services (HHS) intends to focus itsenergies on augmenting healthcare reform by increasingly tying payment to value through alternative paymentmodels; changing the way care is delivered through greater teamwork and integration; and harnessing the power ofinformation to improve care for patients.

2. CMS proposes to test new Medicare Part B prescription drug models to improve quality of care and deliver better value for Medicare beneficiaries. 2016. Retrieved May, 2016, from https://www.cms.gov/Newsroom/ MediaReleaseDatabase/Press-releases/2016-Pressreleases-items/2016-03-08.html

3. Wittington JW, Nolan K, Ninon L, Torres T. Pursuing the Triple Aim: the first 7 years. Milbank Q. 2015;93(2):263300.

4. Berwick D, Nolan T, Whittington J. The Triple Aim: care, cost, and quality. Health Aff. 2008;27(3):759-69.

$5 . \bullet$ Porter ME. what is value in healthcare? N Engl J Med. 2010;363:2477-81.

One of the more cited seminal articles about creating and measuring healthcare value written by the economist, Michael Porter.

6. Developing New Pediatric Quality Measures. Schwalenstocker, E. Retrieved May, 2016, from https:// www.childrenshospitals.org/newsroom/childrenshospitals-today/issue-archive/issues/spring-2014/ articles/developing-new-pediatric-quality-measures.

7. Bending the Value Curve. Fieldston, E, Marar M, Jonas J., Hospital Pediatrics. July 2014, Volume 4/Issue 4. Retrieved May, 2016, from http://hosppeds. aappublications.org/content/4/4/261.

8. Waters P. Value in pediatric orthopaedic surgery health care: the role of time-driven activity-based cost accounting (TDABC) and standardized clinical assessment and management plans (SCAMPs). J Pediatr Orthop. 2015;35:S45-7.

9. Deshpande J, Green A, Schellhase D. Measuring what really matters in patient safety. Curr Treat Options Peds. 2015;1:286-97.

10. Kelleher, KJ, Cooper J, Deans K, et al. Cost saving and quality of care in a pediatric accountable care organization. Pediatrics. 2015;135 3.

11. Children's Health Spending: 2010-2014. 2016. Retrieved May, 2016, from http://www.healthcostinstitute.org/files/ 2016 Kids Report 5.16.16.pdf.

12. Squires D, Anderson C. 2015. U.S. health care from a global perspective. Retrieved May, 2016, from http:// www.commonwealthfund.org/publications/issue-briefs/ 2015/oct/us-health-care-from-a-global-perspective. 